\title{
FAKTOR PENGARUH LUAS BANGUNAN RUMAH TINGGAL TERHADAP BANGUNAN RENDAH KARBON
}

\author{
Prasetyo \\ Dosen Pengajar Program Studi Teknik Arsitektur, Fakultas Teknik \\ Universitas 17 Agustus 1945 Samarinda \\ (prasetyo@untag-smd.ac.id)
}

\begin{abstract}
ABSTRAK
Peranan energy yang sangat penting dalam kehidupan masyarakat karena energi merupakan parameter penting bagi pembangunan dan pertumbuhan ekonomi. Hampir semua sektor kehidupan (industri, transportasi, rumah tangga, jasa, dll) tidak bisa dipisahkan dari energi. Di sektor rumah tangga, energi digunakan untuk penerangan, memasak, pendingin atau pemanas dan penggunaan kendaraan bermotor untuk aktivitas sehari-hari. Saat ini semakin banyak peralatan rumah tangga yang menggunakan energi untuk pemanfaatan sehingga meningkatkan emisi. Masalah yang sering muncul terkait konsumsi energi dari sektor rumah tangga tersebut adalah disparitas (perbedaan) konsumsi energi masyarakat miskin dengan masyarakat kaya, artinya bahwa masyarakat yang kaya akan berperilaku untuk memperbesar rumah hunia, dan dipastikan fasilitas rumah sebagai rasa kenyamanan akan semakin besar akan tetapi masyarakat kaya tersebut tidak bisa melihat pencemaran udara lingkungannya.
\end{abstract}

Kata Kunci : Luas bangunan, bangunan rendah karbon

\begin{abstract}
The role of energy is very important in people's lives because energy is an important parameter for economic development and growth. Almost all sectors of life (industry, transportation, household, services, etc.) cannot be separated from energy. In the household sector, energy is used for lighting, cooking, cooling or heating and the use of motorized vehicles for daily activities. Currently, more and more household appliances use energy for utilization, thereby increasing emissions. The problem that often arises related to energy consumption from the household sector is the disparity (difference) in the energy consumption of the poor and the rich, meaning that rich people will behave to enlarge their homes, and it is certain that home facilities as a sense of comfort will be greater but society the rich cannot see the air pollution in their environment.
\end{abstract}

Keywords: Building area, low carbon building

\section{PENDAHULUAN}

Bangunan rendah karbon mengutamakan kegiatan yang meminimalkan pelepasan karbon dioksida (emisi CO2) ke udara (atmosfer) merupakan penyumbang terbesar gas rumah kaca (pemanasan global).

Kenaikan suhu bumi akan mempercepat pencairan lapisan es di kutub bumi yang seiring dengan kenaikan permukaan air laut, sehingga perubahan cuaca semakin ekstrem, kepunahan spesies tumbuhan dan hewan, dan penyakit (lingkungan) semakin sulit dikendalikan. 
Perubahan iklim dunia merupakan tantangan yang paling serius yang dihadapi pada abad 21. Sebagian besar pakar lingkungan sepakat bahwa terjadinya perubahan iklim merupakan salah satu dampak dari pemanasan global. Pemanasan global (global warming) merupakan salah satu isu internasional yang dewasa ini banyak mendapat sorotan dari berbagai macam kalangan. Pemanasan global dapat terjadi karena adanya efek rumah kaca. Gas rumah kaca yang berada di atmosfer bumi dapat disamakan dengan tabir kaca pada pertanian yang menggunakan rumah kaca.

Pembangunan rendah karbon diwujudkan dalam bentuk pembangunan yang berkelanjutan dan dapat diwujudkan seperti pembangunan kota rendah karbon (KRK). Pembangunan berkelanjutan adalah pembangunan yang dilakukan berdasarkan prinsip memenuhi kebutuhan sekarang tanpa mengorbankan pemenuhan kebutuhan generasi mendatang (Gru Brundtland, 1987).

Pada bangunan rumah tinggal sangat tergantung dengan penggunaan energi yang antara lain untuk penerangan, memasak, pendingin atau penghangat ruangan apalagi dewasa ini semakin banyak peralatan rumah tangga yang menggunakan energy, dari kegiatan rumah tangga ini akan menimbulkan emisi $\mathrm{CO} 2$.

Konsumsi energi dari sektor rumah tangga makin meningkat dengan persoalan yang sering muncul terkait adalah adanya disparitas (perbedaan) dalam konsumsi energi dari kelompok masyarakat miskin dengan kelompok masyarakat kaya serta penggunaan kendaraan untuk aktifitas sehari-hari sehingga dalam pemanfaatannya akan meningkatkan emisi yang dihasilkan akan mengakibatkan suhu permukaan bumi menjadi meningkat. Meningkatnya suhu udara ini akan dapat mengakibatkan adanya perubahan iklim yang sangat ekstrim di bumi.

Jejak karbon sekunder dihasilkan dari perlatan-peralatan elektronik rumah tangga dimana peralatan elektronik ini dapat berfungsi dengan menggunakan daya listrik. Hal ini didapat dari daur hidup dari produk-produk yang kita gunakan, seperti konsumsi listrik.

\section{TINJAUAN PUSTAKA}

Emisi karbon adalah gas buang atau senyawa ke dalam udara yang dihasilkan dari suatu aktivitas dimana besarannya dinyatakan dalam ton karbon atau ton karbondioksida ekuivalen (CO2) secara langsung maupun tidak langsung yang dari penggunaan/ proses produk dan jasa dalam kehidupan sehari-hari. Berbagai aktivitas diatas yang dapat dikelompokan dalam aktivitas domestik, transportasi, pengelolaan limbah dan konfigurasi bahan bangunan serta sarana dan prasarana lingkungan.

Timbulan emisi CO2 pada pembangunan rumah adalah berasal dari konsumsi energy pada proses pembangunan rumah (embodied energy), yakni: mulai dari pabrikasi bahan bangunan, konstruksi bangunan, penggunaan energi dari aktifitas domestik, sampai dengan domisili pasca hunian (operational energy). Untuk mengetahui besaran emisi CO2 dari pembangunan rumah perlu diketahui faktor-faktor yang mempengaruhi setiap tahapan dalam proses pembangunan rumah tersebut. Emisi $\mathrm{CO} 2$ pada pembangunan rumah dihasilkan mulai dari proses pembuatan bahan bangunan dan transportasi bahan bangunan, penggunaan peralatan selama proses konstruksi sampai dengan aktifitas rumah tangga ketika rumah tersebut dihuni. 
Pengendalian emisi karbon pada skala lokal, regional dan nasional menjadi tujuan penting untuk mengurangi emisi karbon yang berdampak pada kenaikan iklim global. Terdapat 2 (dua) mekanisme untuk menurunkan CO2 secara alami, yaitu penghijauan dan badan air seperti sungai atau danau. Penghijauan dapat berupa hutan kota, jalur hijau, taman kota, kebun dan halaman.

Perubahan alih fungsi lahan serta kondisi fisik lingkungan juga berpengaruh terhadap timbulan gas $\mathrm{CO} 2$, terlebih lagi dengan semakin berkurangnya ruang terbuka hijau maupun vegetasi yang ada pada suatu lingkungan/ kawasan.

Berbagai konsep dalam desain arsitektur termasuk perumahan juga harus mendukung pembangunan yang menekankan pentingnya efisiensi penggunaan energi, efisiensi penggunaan lahan, efisisensi penggunaan material, penggunaan teknologi dan material baru, dan manajemen limbah. Semuanya diperlukan sebagai upaya dalam pengendalian emisi karbon.

Salah satu tantangan yang harus dihadapi dalam pembangunan perumahan adalah bagaimana memperbaiki perubahan lingkungan tanpa mengorbankan kebutuhan pembangunan ekonomi dan keadilan sosial. Beberapa pendekatan dalam pembangunan perumahan telah dikembangkan guna menekan emisi karbon ataupun jejak karbon konstruksi tersebut.

Secara umum, kontribusi emisi karbon dengan jejak karbon yang ditimbulkannya dapat dilihat pada persamaan berikut:

\section{Jejak Karbon $=$ Faktor Emisi x Satuan Aktivitas}

- Faktor Emisi adalah besaran emisi gas rumah kaca (GRK) yang dilepaskan ke atmosfer per satuan aktivitas tertentu.

\section{METODE PENELITIAN}

\section{Jenis Penelitian.}

Analisis dalam penelitian ini dilakukan untuk mengetahui kesesuaian implementasi luas bangunan rumah tinggal dengan pendekatan kualitatif, jenis deskriptif. Sumber data yang digunakan adalah sumber data primer dan data sekunder. Disamping itu penulis juga menggunakan penelitian observasi, wawancara dan dokumentasi guna memperoleh data primer.

\section{Tempat Penelitian}

Penelitian ini dilakukan pada bangunan rumah tinggal di permukiman baik yang dibangun oleh developer ataupun dibangun sendiri dengan menggunakan jasa kontraktor dikota Samarinda. 


\section{Subyek Penelitian}

Penggunaan energi dalam rumah tangga meliputi besarnya listrik terpasang dan penggunaan listrik rumah tangga dan besarnya pembanyaran penggunaan listrik rata-rata pada tiap bulannya pada bangunan rumah tinggal sederhana, bangunan menengah dan bangunan yang besar, parallel dengan luas bangunan gedungnya dari $36 \mathrm{~m} 2$ dan $>120$ $\mathrm{m} 2$.

Penggunaan material bahan bangunan yang terpasang pada bangunan rumah tinggal diantaranya pada material lantai, material dinding dan material atap.

\section{Prosedur}

Yaitu langkah-langkah yang dipakai untuk mengumpulkan data guna menjawab pertanyaan penelitian yang diajukan didalam penelitian ini, dengan pembahasannya tentang lokasi dan subyek pupulasi/sampel penelitian, desain penelitian (tahap persiapan, tahap pelaksanaan dan tahap pelaporan) dan justifikasi, definisi operasional, instrument penelitian, proses pengembangan instrument, teknik pengumpulan data dan alasan rasionalnya dan analisis data.

\section{Data dan Instrumen}

Data yang diperoleh dalam penelitian ini berupa data deskriptif dan visual (foto). Data diperoleh dengan peneliti sebagai instrumen utama yang dibantu dengan instrumen pendukung, seperti pedoman observasi dan pedoman wawancara.

Pengambilan data di lapangan dilakukan dengan teknik observasi nonpartisipan dan tidak terstruktur, wawancara mendalam (in depth interview), dan dokumentasi.

\section{HASIL DAN PEMBAHASAN}

Emisi CO2 merupakan nilai rata-rata suatu parameter pencemar udara yang dikeluarkan sumber spesifik. Faktor-faktor ini biasanya dinyatakan sebagai berat polutan dibagi dengan satuan berat, volume, jarak, atau lamanya aktivitas yang dapat mengeluarkan polutan. Adanya variasi tersebut, menimbulkan ekspresi faktor emisi dengan unit yang berbeda (Anonim, 2010)

Emisi CO2 dalam penelitian ini adalah emisi CO2 dari kegiatan rumah tangga dan material pembangunan rumah tinggal yang dapat dilihat dari jejak karbon konstruksi. Jejak karbon adalah suatu ukuran jumlah total dari hasil emisi karbondioksida yang dihasilkan secara langsung maupun tidak langsung yang disebabkan oleh kegiatan dan aktivitas sehari-hari (Wiedemann dan Minx, 2007).

Penggunaan energi yang berlebihan mempunyai dampak negatif yaitu meningkatkan jumlah emisi CO2. Emisi CO2 yang berlebihan dapat menyebabkan kerusakan lingkungan serta pemanasan global.

Variable yang akan digunakan sebagai gambaran penelitian ini di kelompokan menjadi 2 kelompok variable yaitu :

1. Kegiatan Dosmetik yaitu kegiatan yang ada di dalam bangunan rumah yang menggunakan energy listrik diantaranya : 
- Biaya rata-rata listrik tiap bulan.

- Jenis lampu penerangan yang digunakan

- Peralatan elektronik yang digunakan

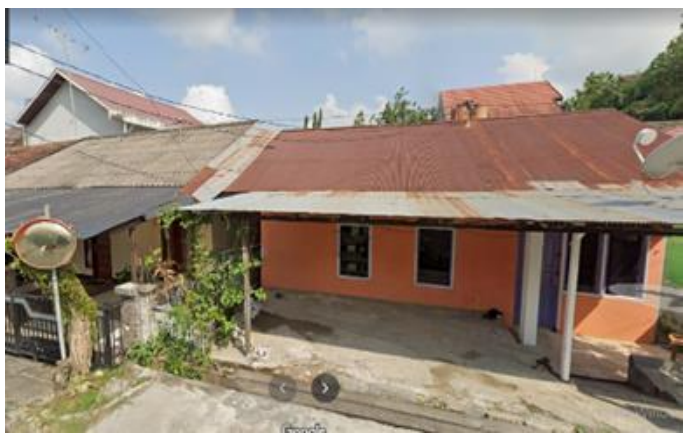

Gambar 1. Bangunan Sederhana

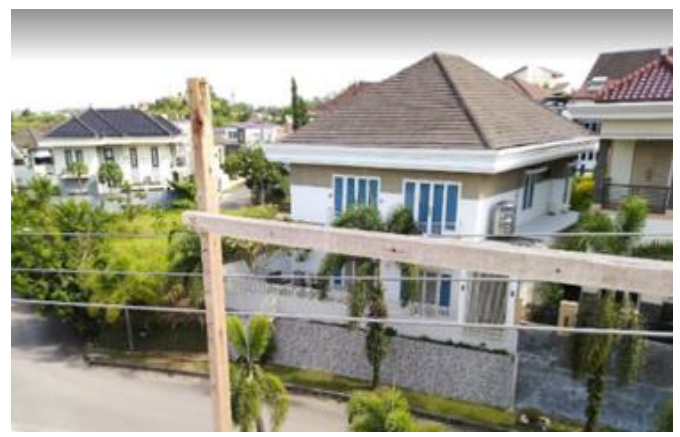

Gambar 3. Bangunan Mewah

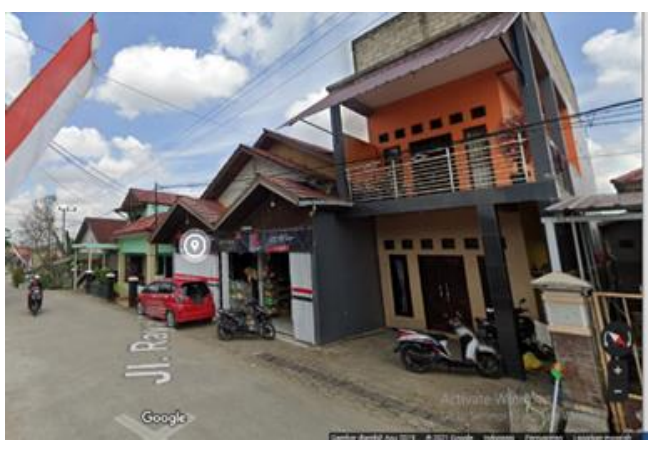

Gambar 2. Bangunan Menengah keatas

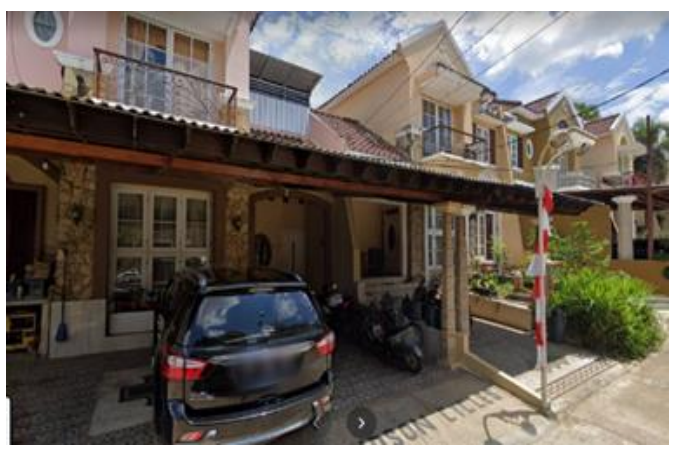

Gambar.4. Bangunan Mewah

2. Proses konstruksi/ pembangunan perumahan maupun lingkungan termasuk salah satu aktivitas yang banyak mengkonsumsi energi sehingga menghasilkan emisi karbon yang cukup besar.

Bahan Bangunan yang terpasang pada bangunan rumah tinggal yang menyumbang besaran emisi CO2 diantaranya :

- Material lantai

- Material dinding

- Material penutup atap

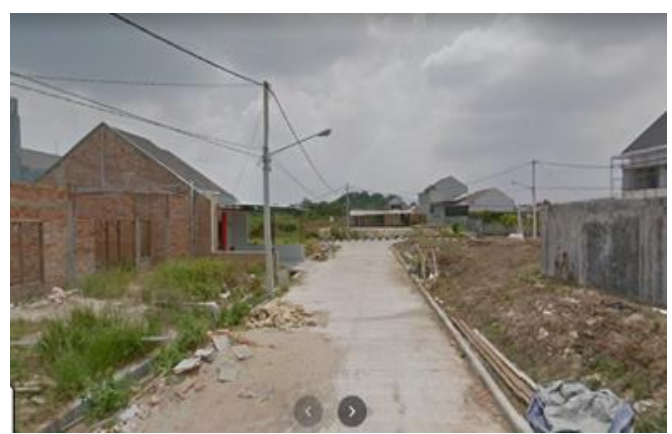

Gambar 5. Material Bangunan

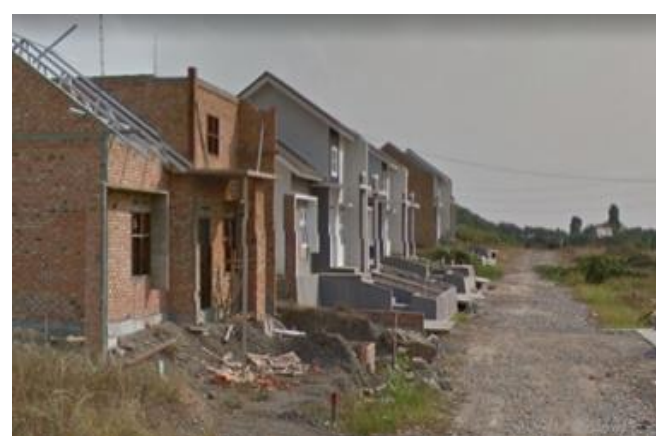

Gambar 6. Material Bangunan 
Aspek signifikan Emisi Karbon Bangunan Rumah menengah kebawah.

Tabel 1. Aspek Signifikan Emisi Karbon Bangunan Rumah

\begin{tabular}{|c|c|c|c|c|c|c|}
\hline \multirow{2}{*}{$\begin{array}{c}\text { Kelompok } \\
\text { Variabel }\end{array}$} & \multirow{2}{*}{ Variabel Utama } & \multirow{2}{*}{ Variabel Turunan } & \multicolumn{4}{|c|}{ Bangunan Rumah di Kota Samarinda } \\
\hline & & & Sederhana & Menengah & Menengah & Mewah \\
\hline \multirow{4}{*}{ Kegiatan Domestik } & \multirow{4}{*}{$\begin{array}{l}\text { Emisi CO2 dari pemakaian } \\
\text { listrik(kg/tahun) }\end{array}$} & biaya rata-rata listrik/bulan (ribu Rp. & 560,00 & 960,00 & $1.720,00$ & $2.000,00$ \\
\hline & & listrik terpasang (KWh) & 900 & 1300 & 2200 & 3300 \\
\hline & & Jenis lampu penerangan & LED & LED & LED & LED \\
\hline & & peralatan elektronik yg digunakan & $\begin{array}{l}\text { kipas angin, charger } \\
\text { HP, TV }\end{array}$ & $\begin{array}{l}\text { kipas angin, charger } \\
\mathrm{HP}, \mathrm{TV}, \mathrm{AC}\end{array}$ & $\begin{array}{l}\text { kipas angin, charger } \\
\mathrm{HP}, \mathrm{TV}, \mathrm{AC}\end{array}$ & $\begin{array}{l}\text { kipas angin, charger } \\
\mathrm{HP}, \mathrm{TV}, \mathrm{AC}\end{array}$ \\
\hline \multirow{7}{*}{ Bahan Bangunan } & \multirow{2}{*}{$\begin{array}{l}\text { Emisi CO2 dari ubin } \\
\text { lantai(kg/tahun) }\end{array}$} & Luas lantai m2 & 36 & 70 & 90 & 120 \\
\hline & & jenis penutup lantai & Keramik & Keramik & Keramik & Keramik \\
\hline & \multirow{2}{*}{$\begin{array}{l}\text { Emisi CO2 dari dinding } \\
\text { (kggtahun) }\end{array}$} & bahan material dinding & Bataco & bata & bata & bata \\
\hline & & luas bukaan & $<75 \mathrm{~m} 2$ & $>75 \mathrm{~m} 2$ & $>75 \mathrm{~m} 2$ & $>75 \mathrm{~m} 2$ \\
\hline & \multirow{3}{*}{$\begin{array}{l}\text { Emisi CO2 dari genteng } \\
\qquad \text { (kg/tahun) }\end{array}$} & luas atap & $<200 \mathrm{~m} 2$ & $>200 \mathrm{~m} 2$ & $>200 \mathrm{~m} 2$ & $>200 \mathrm{~m} 2$ \\
\hline & & bahan struktur atap & Baja ringan & Baja ringan & Baja ringan & Kayu \\
\hline & & bahan penutup atap & Seng/Metal calour & $\begin{array}{r}\text { Seng/Metal } \\
\text { calour/genteng } \\
\text { tanah }\end{array}$ & genteng tanah & genteng tanah \\
\hline
\end{tabular}

(Sumber: Hasil Survei Lapangan, Maret 2021)

Luas lantai yang mencerminkan besaran bangunan rumah tinggal semakin luas akan diikuti dengan kebutuhan energy yang meningkat pula, hal ini juga menunjukan emisi $\mathrm{CO} 2$ semakin meninggi.

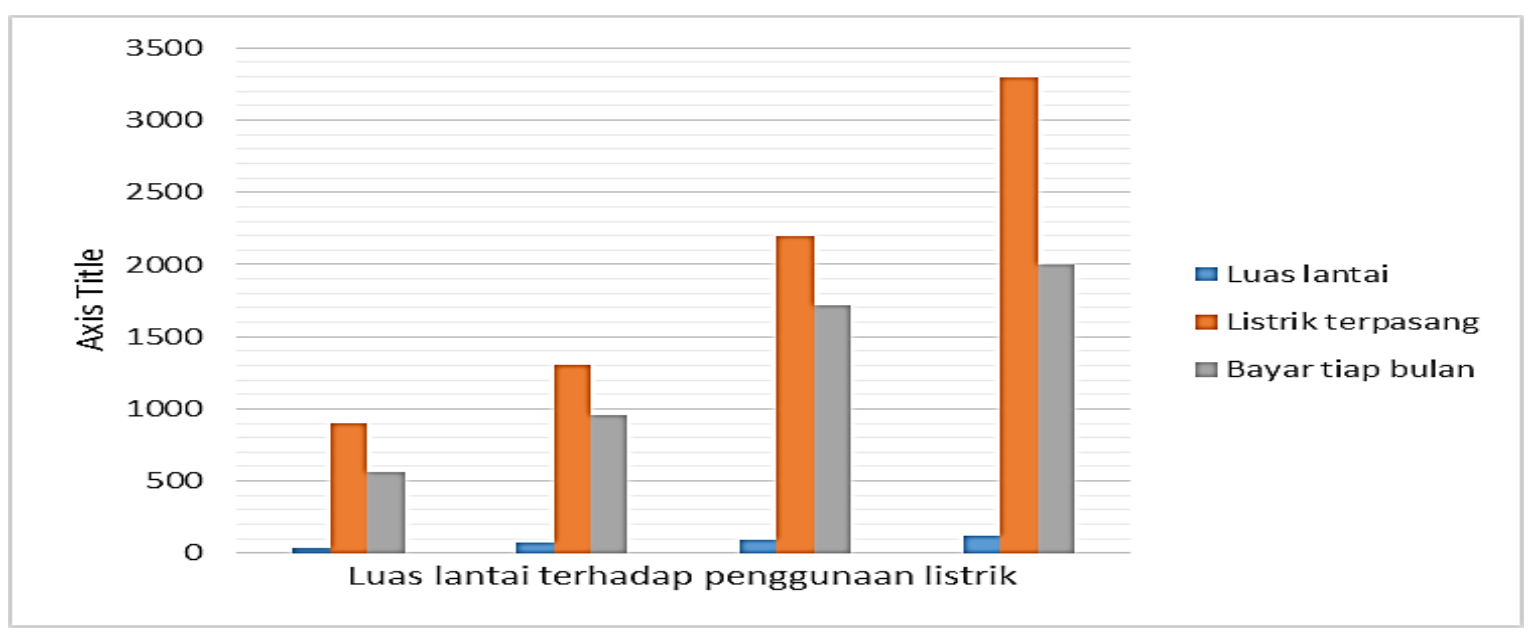

Gambar 7. Grafik luas lantai terhadap penggunaan listrik 
Aspek pengadaan bahan bangunan menyumbang emisi karbon yang paling banyak dibandingkan dengan aspek lainnya. Sedangkan aspek pilihan metode konstruksi baik on site maupun off site memberikan pengaruh/ kontribusi yang paling sedikit dibandingkan aspek lainnya bahan bangunan juga membutuhkan banyak energi untuk proses pengadaannya akan memberikan kontribusi yang signifikan pada emisi karbon konstruksi.

Dengan demikian faktor emisi karbon pada proses pengadaan material bangunan ke lokasi konstruksi akan mempengaruhi jejak karbon konstruksi pembangunan perumahan tersebut.

Tabel faktor emisi karbon pengadaan bahan bangunan dibawah ini dapat dijadikan pertimbangan dalam memilih material bahan bangunan rumah tinggal.

Tabel 2. Faktor Emisi Karbon Pengadaan Bahan Bangunan

\begin{tabular}{|c|c|c|c|}
\hline No. & Bahan Bangunan & Faktor Emisi & Satuan \\
\hline 1 & Asbes & $1.668,6$ & $\mathrm{Kg} / \mathrm{m} 3$ \\
\hline 2 & Baja Tulangan & $12.207,0$ & $\mathrm{Kg} / \mathrm{m} 3$ \\
\hline 3 & Bata & 290,8 & $\mathrm{Kg} / \mathrm{m} 3$ \\
\hline 4 & Batako & 153,9 & $\mathrm{Kg} / \mathrm{m} 3$ \\
\hline 5 & Batu belah & - & \\
\hline 6 & Beton & 333,6 & $\mathrm{Kg} / \mathrm{m} 3$ \\
\hline 7 & Beton bertulang & - & \\
\hline 8 & Beton ringan dengan Fly bottom Ash & 302,5 & $\mathrm{Kg} / \mathrm{m} 3$ \\
\hline 9 & Beton ringan & 196,9 & $\mathrm{Kg} / \mathrm{m} 3$ \\
\hline 10 & Genteng Beton & 564,0 & $\mathrm{~K} g / \mathrm{m}^{3}$ \\
\hline 11 & Gypsum board & 301,8 & $\mathrm{Kg} / \mathrm{m} 3$ \\
\hline 12 & Kaca & $1.380,5$ & $\mathrm{Kg} / \mathrm{m} 3$ \\
\hline 13 & Kayu & 204,5 & $\mathrm{Kg} / \mathrm{m} 3$ \\
\hline 14 & Keramik & $1.920,0$ & $\mathrm{~K} \mathbf{g} / \mathrm{m}_{3}$ \\
\hline 15 & Mortar & 418,0 & $\mathrm{Kg} / \mathrm{m} 3$ \\
\hline 16 & Pasir & 51,0 & $\mathrm{~K} g / \mathrm{m}_{3}$ \\
\hline 17 & Plywood & 650,1 & $\mathrm{Kg} / \mathrm{m} 3$ \\
\hline 18 & Portland cement & - & \\
\hline
\end{tabular}

Oleh karena itu setiap pembangunan perumahan, mulai dari perencanaan hingga penyelenggaraan pembangunan harus mempertimbangkan keseimbangan terpadu dalam memanfaatkan sumber daya yang ada namun terbatas dan berbasis rendah emisi karbon $(\mathrm{CO} 2)$. 


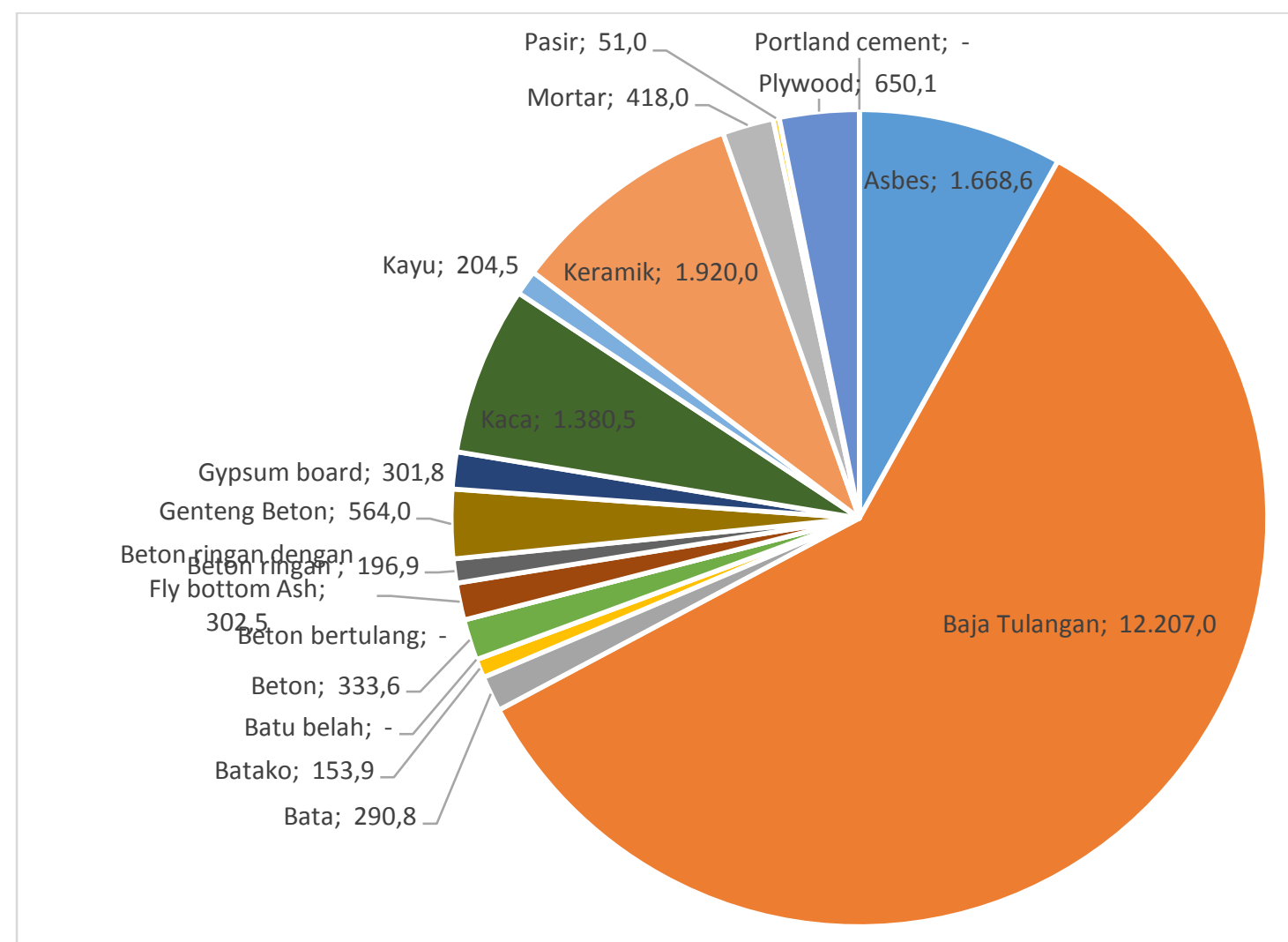

Gambar 8. Faktor Emisi Karbon Pengadaan Bahan Bangunan

Dari data diatas menunjukan bahan bangunan penyumbang emisi karbon yang terbesar adalah material dengan bahan baku semen, keramik dan baja.

Sehingga diperlukan rekayasa maupun efisiensi dalam penggunaan bahan-bahan tersebut melalui daur ulang material dan bangunan tahan lama, atau penghematan energi melalui perbaikan sistem bahan dan konstruksi bangunan, serta dapat dilakukan optimalisasi sistem jaringan lalu lintas yang ramah lingkungan yang dapat berguna bagi pengendalian emisi karbon.

\section{Kendala di Lapangan.}

Terdapat beberapa kenyataan di lapangan kemungkinan bisa menjadi factor timbulan emisi karbondioksida (CO2) dilapangan, yaitu :

1. Pencerminan besaran bangunan dan luas lantai yang menggambarkan tingkat ekonomi pemilik bangunan tersebut dan biasanya fasilitas pelengkap untuk kenyamanan dalam keseharian akan semakin besar sehingga akan menunjukan semakin besar timbulan emisi $\mathrm{CO} 2$.

2. Penggunaan material bangunan yang belum ramah lingkungan untuk rumah tinggalnya yang tidak disadari makin tambah factor timbulan emisi $\mathrm{CO} 2$ nya.

3. Penggunaan lampu LED yang rata-rata sudah lebih banyak di masyarakat Kota Samarinda dapat menunjukan pengurangan emisi CO2, akan tetapi kebanyakan 
JURNAL KACAPURI

JURNAL KEILMUAN TEKNIK SIPIL

Volume 4 Nomor 2 Edisi Desember 2021

masyarakat yang dipertimbangkan adalah pengaruh pembayaran listrik tiap bulannya.

\section{PENUTUP}

Dari uraian tentang Pengaruh Luas Bangunan Rumah Tinggal terhadap besaran energy yang digunakan dapat disimpulkan sebagai berikut :

1. Semakin besar bangunan gedung rumah akan linier dengan fasilitas untuk kenyamanan bangunan tersebut, seperti penggunaan AC akan digunakan bila tanpa didesain bangunan yang ramah lingkungan sehingga mempunyai andil besar dalam produksi emisi karbon $\mathrm{CO} 2$.

2. Di masyarakat Kota Samarinda telah sadar diri dan manfaat nyata dari beban pembayaran PLN sehingga untuk menggunakan lampu penerangan rumah telah menggunakan jenis lampu LED.

3. Strategi dalam membangunan rumah tinggal haruslah bijaksana, memperhatikan kelestarian lingkungan serta keberlanjutan sumber daya maupun bahan bangunan, akan dapat menekan atau mengendalikan emisi karbon konstruksi yaitu dengan mempertimbangkan penggunan lahan pekarangan atau site.

4. Emisi karbon yang rendah akan meninggalkan jejak karbon yang relatif kecil pada suatu lingkungan sehingga dapat mengurangi pemanasan global.

Saran yang dapat disampaikan untuk agar dapat berperan dalam mengurangi emisi $\mathrm{CO} 2$ dimulai dari komunitas terkecil, yaitu dari rumah kita yang menjadi tempat tinggal kita dengan mempertimbangkan :

- Mengatur penggunaan lahan pekarangan atau site dengan perbandingan antara bangunan lebih kecil dari lahan sekitarnya.

- Hendaknya mempertimbangkan tata massa bangunan dengan arena diluar bangunan dengan lingkungan hijau agar tercapai system pencahaayaan dan penghawaan alami.

- Material bahan bangunan yang dipakai atau meminimalis material bahan bangunan yang ber potensi menambah emisi CO2. Yaitu material dengan bahan baku semen, keramik dan baja.

- Mempertimbangkan tata cahaya dan tata penghawaan dalam tata ruang bangunan rumah agar menghindari penambahan fasilitas kenyamanan seperti AC yang akan menjadi menambah timbulan emisi $\mathrm{CO} 2$.

\section{DAFTAR PUSTAKA}

Muhdany Yusuf Laksono, Harian Kompas, 2021, Ini 5 Bangunan Rendah Karbon di Dunia, Jakarta.

GBPN News, 2021, 7 Key Strategies to Decarbonise the Built Environment Trough Policy Reform, (https://www.gbpn.org/7-key-strategies-to-decarbonise-the-builtenvironment-through-policy-reform/), diakses 5 November 2021.

Atjeng Kadaryana, 2018, Direktorat Lingkungan Hidup Kementrian PPN/BAPPENAS, Pembangunan Rendah Karbon, Makasar. 
Ervianto, Wulfram I. 2012, Selamatkan Bumi Melalui Konstruksi Hijau, Perencana-an, Pengadaan, Konstruksi \& Operasi, Yogyakarta.

Wuryanti, Wahyu, 2012, Keputusan Multikriteria dalam Menilai Konstruksi Rumah Tinggal terhadap Lingkungan, Jurnal Permukiman, Volume 7 Nomor 2, Agustus 2012, ISSN 1907- 4352.

Bribian, et al., 2011, Li fe Cycle Assessment of Building Materials: Comparative Analysis of Energy and Environmental Impacts and Evaluation of The Eco-Efficiency Improvement, Building and Environment 46.

Priana Sudjono, Chendy Octaviana Yudhi, Jurnal Teknik Lingkungan Volume 17 Nomor 2, Oktober 2011 (Hal 98-109), Estimasi Emisi CO2 dari Pembangunan berbagai ukuran Rumah Sederhana, (https://journals.itb.ac.id/index.php/jtl/article/ download/8233/3305/24595), diakses 25 Nopember 2021.

Chen D., Syme M., Seo S., Chan W. Y., Zhou M. and Meddings S, 2010, Development of An Embodied CO2 Emission Module for Accurate, Forest and Wood Product Australia, CSIRO Sustainable Ecosystems, Australia

Siti Zubaidah Kurdi, Jurnal Permukiman p-ISSN 1907-4352 Vol 3, No 2 (2008), Pengaruh Emisi CO2 dari sektor Perumahan Perkotaan terhadap Kualitas Lingkungan Global, Jakarta.

Velma I. Grover, Natural Resource Consultant, (2004), Climate Change Five Years after Kyoto, Hamilton,ON Canada.

Failasuf Herman Hendra, 2016, Seminar Nasional Sains dan Teknologi Terapan IV Institut Teknologi Adhi Tama Surabaya ISBN 978-602-98569-1-0, Pembangunan Perumahan Rendah Emisi Karbon di Surabaya Timur, Surabaya.

Gina Ridhia Rahma, December 2019, ResearchGate, (https://www.researchgate.net /publication/338107990_Pembangunan_Rendah_Karbon_Menuju_Indonesia_yan g_Lebih_Baik), diakses 25 Nopember 2021. 